\title{
Stereochemical Assignment of ${ }^{13}$ C NMR Spectra of Predominantly Syndiotactic Polystyrene
}

\author{
Junting Xu, ${ }^{\dagger}$ Jianying OuYang, ${ }^{*}$ Zhiqiang Fan, Dequan ChEN, ${ }^{*}$ \\ Linxian FENG, and Yiqing YANG*
}

\begin{abstract}
Department of Polymer Science and Engineering, Zhejiang University, Hangzhou 310027, People's Republic of China * Shanghai Research Institute of Petrochemical Technology, Shanghai 201208, People's Republic of China
\end{abstract}

(Received February 16, 1998)

\begin{abstract}
In the present work, predominantly syndiotactic polystyrene samples were prepared with different catalysts and polymerization conditions and the obtained polymers were used for assignments of stereochemical structures of polystyrene. Assignment was carried out by comparison of ${ }^{13} \mathrm{C}$ NMR spectra of polystyrenes with different syndiotacticity and based on polymerization mechanism. Assignments were also compared with results in the previous work.
\end{abstract} KEY WORDS Polystyrene $/{ }^{13} \mathrm{C}$ Nuclear Magnetic Resonance / Assignment /

The ${ }^{13} \mathrm{C}$ NMR spectrum of polystyrene was first reported by Johnson et al. ${ }^{1}$ and the assignment of ${ }^{13} \mathrm{C}$ NMR spectrum of polystyrene has been carried out by many researchers. ${ }^{2-6}$ However, there are still many controversies and the stereochemical structures of polystyrene are far from full understanding. The assignments of tetrad are different in ref $2-5$.

Generally there are two methods for the assignment of ${ }^{13} \mathrm{C}$ NMR spectrum of polystyrene in previous work. First, assignment was made by calculating the intensity of resonances based on Bernoullian or Markovian statistics model and comparing calculated values with observed ones. ${ }^{2-4}$ However it is difficult in this method to assign the peaks with similar intensity, especially weak resonances. Secondly, through comparing the ${ }^{13} \mathrm{C}$ NMR spectra of polystyrenes with different tacticity, assignment was also performed. ${ }^{5}$ Nevertheless, most of the samples in previous work were atactic or isotactic-rich, and predominantly syndiotactic sample was rarely reported. This leads to ambiguous assignments of racemicrich sequences. Moreover, since stereochemical structures of polymer are strongly dependent on the polymerization mechanism (active-site-controlled or chain-end-controlled), the types of stereochemical sequences in the polymer chain and relative ratios among them provide useful information for assignment.

In the present work, predominantly syndiotactic polystyrene samples prepared with different catalysts and polymerization conditions were used for the assignments of stereochemical structures of polystyrene. Assignment was carried out by comparing ${ }^{13} \mathrm{C}$ NMR spectra of polystyrenes with different syndiotacticity and based on polymerization mechanism.

\section{EXPERIMENTAL}

\section{Preparation of Polystyrene Samples}

Four polystyrene samples for ${ }^{13} \mathrm{C}$ NMR characterization were prepared with different catalysts and polymerization conditions (Table I). The cocatalyst was methylaluminoxane (MAO). The preparation of polymersupported catalyst was described in elsewhere. ${ }^{7}$

\footnotetext{
† To whom correspondence should be addressed.
}

\section{${ }^{13}$ C NMR Analysis}

100.7 MHz for ${ }^{13} \mathrm{C}$ NMR spectra were recorded on a Bruker AMX-400 spectrometer at $370 \mathrm{~K}$ in pulsed Fourier transformation model. The polymer solutions were prepared by dissolving $\mathrm{ca} .50 \mathrm{mg}$ polymer at $130^{\circ} \mathrm{C}$ in $0.5 \mathrm{ml} \mathrm{C}_{6} \mathrm{D}_{4} \mathrm{Cl}_{2} .1 \%$ hexamethyldisiloxane (HMDS) was added as the internal standard. The pulse angle was $90^{\circ}$, pulse repetition, $10 \mathrm{~s}$, spectral width, $5000 \mathrm{~Hz}$, number of scans, 2000 , and data points, $32 \mathrm{~K}$.

\section{RESULTS AND DISCUSSION}

From the whole ${ }^{13} \mathrm{C}$ NMR spectrum of polystyrene, the methylene region consists of a widely spreading band and is best resolved, while the resonances of other carbon atoms are not sufficiently resolved. In the present work, emphasis was placed on the assignment of methylene region. As reported earlier, in the ${ }^{13} \mathrm{C}$ NMR spectrum of polystyrene the methylene chemical shift sensitivity is basically tetrad. ${ }^{4}$ Some hexad splittings may also be observed. Figure 1 shows the expanded ${ }^{13} \mathrm{C}$ NMR spectra of polystyrenes prepared with different catalysts and polymerization conditions. Stereochemical assignments of the methylene region are summarized in Table II.

Figure 1a is the expanded ${ }^{13} \mathrm{C}$ NMR spectrum of the methylene region of polystyrene prepared with $\mathrm{CpTiCl}_{3}-$ MAO homogeneous catalyst at $\mathrm{Al} / \mathrm{Ti}$ ratio 600 . Based on the ${ }^{13} \mathrm{C}$ NMR spectra of highly syndiotactic and isotactic polystyrene, peaks 8 and 12 are assigned to long racemic sequence ( $\mathrm{rrrr}$ hexad) and long meso sequence ( $\mathrm{mmm}$ tetrad) respectively. Previous work showed that the polymerization mechanism of $\mathrm{CpTiCl}_{3}-\mathrm{MAO}$ ho-

Table I. Catalysts and polymerization conditions for the preparation of samples

\begin{tabular}{|c|c|c|c|c|}
\hline \multirow{2}{*}{ Samples } & \multirow[t]{2}{*}{ Catalysts } & $\begin{array}{l}\mathrm{Al} / \mathrm{Ti} \\
\text { ratio }\end{array}$ & $\begin{array}{c}\text { Polym. } \\
\text { temp }\end{array}$ & $\begin{array}{c}\text { Polym. } \\
\text { time }\end{array}$ \\
\hline & & $\mathrm{mol} \mathrm{mol}^{-1}$ & ${ }^{\circ} \mathrm{C}$ & $\mathrm{h}$ \\
\hline A & $\mathrm{CpTiCl}_{3}$ & 600 & 50 & 5.0 \\
\hline B & $\mathrm{CpTiCl}_{3}$ & 100 & 50 & 5.0 \\
\hline $\mathrm{C}$ & Supported-CpTiCl 3 & 600 & 50 & 5.0 \\
\hline D & Supported-CpTiCl 3 & 100 & 50 & 5.0 \\
\hline
\end{tabular}


${ }^{13}$ C NMR Assignment of Syndiotactic Polystyrene
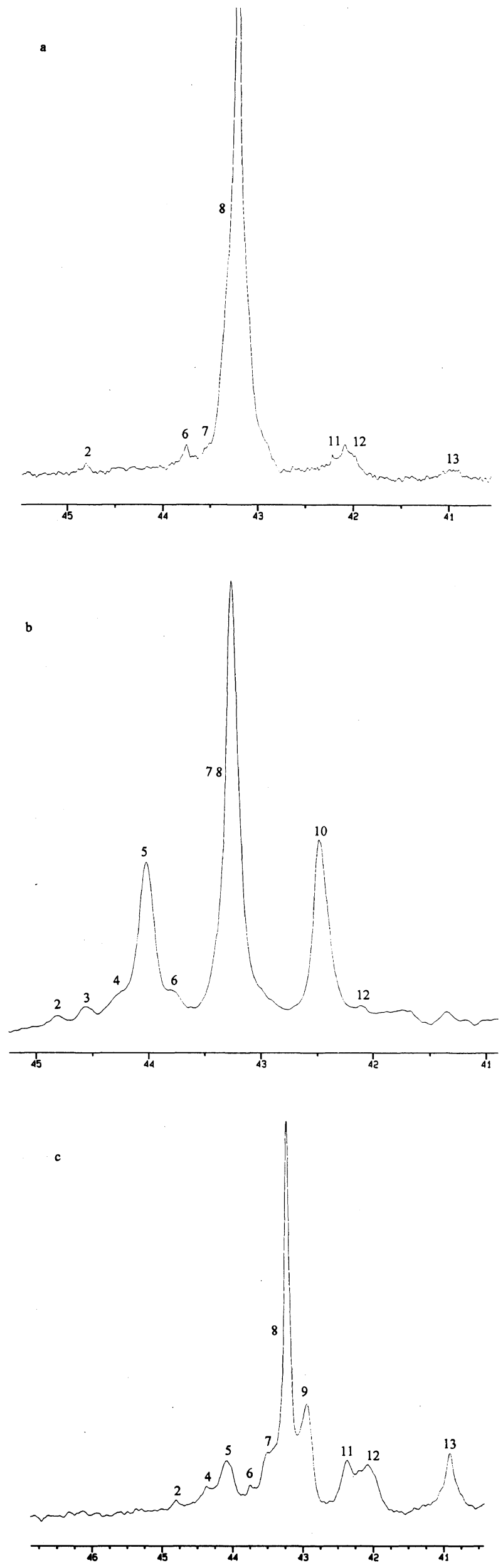

Polym. J., Vol. 30, No. 9, 1998

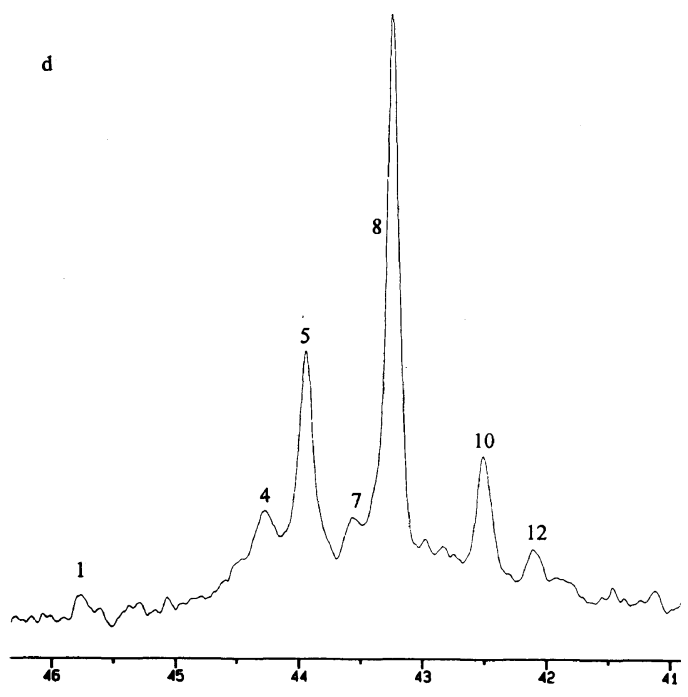

Figure 1. Expanded ${ }^{13} \mathrm{C}$ NMR spectra of the methylene region of (a) sample A, (b) sample C, (c) sample B, and (d) sample D.

Table II. Assignment of ${ }^{13} \mathrm{C}$ NMR spectra of the methylene region of polystyrene

\begin{tabular}{|c|c|c|c|}
\hline \multirow{2}{*}{ Peak No. } & \multicolumn{2}{|c|}{ Assignment } & \multirow{2}{*}{$\frac{\text { Chemical shift }}{\text { ppm }}$} \\
\hline & Tetrads & Hexads & \\
\hline 1 & & $m r m r r$ & 45.8 \\
\hline 2 & $r m r$ & $r r m r r$ & 44.8 \\
\hline 3 & & mrmrm & 44.5 \\
\hline 4 & & $m r m m r+r r m m m$ & 44.3 \\
\hline 5 & $\mathrm{rmm}$ & rrmmr & 44.0 \\
\hline 6 & & mrmmm & 43.7 \\
\hline 7 & & rrrrm & 43.5 \\
\hline 8 & $r r r$ & rrrrr & 43.2 \\
\hline 9 & & mrrrm & 42.9 \\
\hline 10 & $\mathrm{rrm}$ & rrrmm & 42.5 \\
\hline 11 & & $r r r m r$ & 42.3 \\
\hline 12 & $\mathrm{mmm}$ & & 42.1 \\
\hline 13 & $\mathrm{mrm}$ & & 40.9 \\
\hline
\end{tabular}

mogeneous catalyst for syndiospecific polymerization of styrene is chain-end-controlled. ${ }^{8,9}$ Thus the structures like that in Schemes $1 \mathrm{a}, \mathrm{b}$ may be generated. In structure (a), four hexads rrrrr, rrrm, rrrmr, rrmrr can be observed and the ratio of hexad $[\mathrm{rrrrm}]:[\mathrm{rrrmr}]:[\mathrm{rrmrr}]$ is $2: 2: 1 .{ }^{10}$ Structure (b) produces four hexads $m m m m m$, $m m m m r, m m m r m, ~ m m r m m$, and the area ratio of $[\mathrm{mmmmr}]:[\mathrm{mmmrm}]:[\mathrm{mmrmm}]$ is $2: 2: 1$. However, due to low content of meso unit, only tetrads $\mathrm{mmm}$ and $m r m$ are observed. Therefore, seven peaks attributed to five hexads and two tetrads are resolved in Figure 1a.

Figure $1 \mathrm{~b}$ is the expanded ${ }^{13} \mathrm{C}$ NMR spectrum of the methylene region of sample $C$ prepared with a polymer-supported catalyst at $\mathrm{Al} / \mathrm{Ti}$ ratio 600 . This polymer is predominantly syndiotactic, because three major peaks are observed and the intensity of other peaks is very weak in Figure $1 \mathrm{~b}$. This indicates a simple structure of this polymer. It is also observed that the relative intensity of peaks 5 and 10 is close to $1: 1$. From above facts, the structure of this polymer sample and polym- 
a

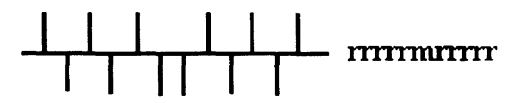

b
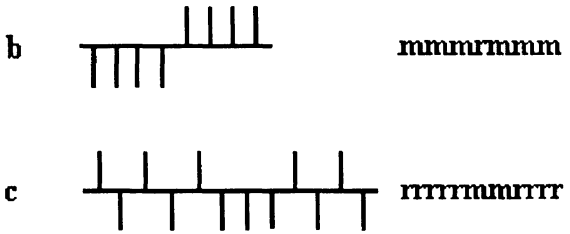

Scheme 1. Possible structural defects in polystyrene chains

erization mechanism of supported catalyst can thus be inferred. ${ }^{10}$ The polymerization mechanism is active-sitecontrolled and sample $\mathrm{C}$ has the structure shown in Scheme 1c, since only in such a polymer structure the absorption of four hexads rrrr, rrrm, rrrmm, and rrmmr is very strong and the area ratio of $[\mathrm{rrrmm}]:[\mathrm{rrmmr}]$ is $1: 1$. Thus peaks 5 and 10 are assigned to $\mathrm{rrmr}$ and $\mathrm{rrmm}$ hexads respectively. Due to the lower syndiotacticity of this sample, the other two minor peaks at $44.5 \mathrm{ppm}$ (peak 3 ) and $44.3 \mathrm{ppm}$ (peak 4) in Figure $1 \mathrm{~b}$ are assigned the splittings of $\mathrm{rmr}$ and $\mathrm{rmm}$ respectively, i.e., $\mathrm{mrmrm}$ and mrmmr + rrmmm

Figures $1 \mathrm{c}$ and $\mathrm{d}$ are the expanded ${ }^{13} \mathrm{C}$ NMR spectra of polystyrene prepared with $\mathrm{CpTiCl}_{3}-\mathrm{MAO}$ and polymer-supported catalyst at $\mathrm{Al} / \mathrm{Ti}=100$. These two samples possess even lower syndiotacticity. In these two spectra, splittings of $r r r$ tetrad can be observed more obviously. Peak 9 at $42.9 \mathrm{ppm}$ is assigned to the other hexad (mrrrm) splitting of rrr tetrad because it is very close to $r r r r$ hexad. A new peak appearing at $45.8 \mathrm{ppm}$ in Figure 1d (peak 1) is attributed to mrmrr hexad, another splitting of $r m r$ tetrad.

The assignments in Table II are similar to those of Kawamura to some extent, ${ }^{5}$ but (1) the major difference lies in the order of $\mathrm{rrr}$ and $\mathrm{rmm}$ tetrads. In Kawamura's assignments $r r$ tetrad is in a lower field than rrm tetrad, whereas the order is reversed in Table II. The assignments of tetrads in Inoue's work were the same as that in the present work. ${ }^{2}(2)$ The sequences of some hexad splittings in $r m r, r m m$, and $r r r$ tetrads differ. In ref 5 hexad splittings were assigned in the order of $m \times x \times m, m \times x \times r, r \times x \times r$ from lower field to higher field, but in the present work the hexad splittings are assigned according to the sequence of $m \times x \times r, r \times x \times r, m \times x \times m$ from lower field to higher field, since the strongest hexad splittings $r \times x \times r$ is found between the hexad splittings of $m \times x \times r$ and $m \times x \times m$.

The hexad splittings of $\mathrm{mmm}$ and $\mathrm{mrm}$ tetrads and part of hexad splitting of $\mathrm{rrm}$ tetrad cannot be resolved in Figure 1, because the polystyrene samples used for assignment are predominantly syndiotactic and content of the meso unit is relatively lower.

Acknowledgment. Financial support from Shanghai Research Institute of Petrochemical Technology and State Education Commission of China is gratefully acknowledged.

\section{REFERENCES}

1. L. F. Johnson, F. Heatley, and F. A. Bovey, Macromolecules, 3, 175 (1970).

2. Y. Inoue, A. Nishioka, and R. Chûjô, Makromol. Chem., 156, 207 (1972).

3. K. Matsuzaki, T. Uryu, T. Seki, K. Osada, and T. Kawamura, Makromol. Chem., 176, 3051 (1975).

4. J. C. Randall, "Polymer Sequence Determination: Carbon-13 NMR Method," Academic Press, New York, N.Y., 1978.

5. T. Kawamura, N. Toshima, and K. Matsuzaki, Macromol. Chem., Rapid Commun., 15, 479 (1994).

6. H. Sato and Y. Tanaka, Am. Chem. Soc. Symp. Ser., 247, 181 (1984).

7. J. T. Xu, J. Y. Ouyang, Z. Q. Fan, D. Q. Cheng, and L. X. Feng, in preparation.

8. P. Ammendola, P. Longo, and A. Zambelli, Gazz. Chim. Ital., 117, 65 (1987).

9. A. Grassi, C. Pellechia, and L. Oliva, Macromol. Chem. Phys., 196, 1093 (1995).

10. F. A. Bovey, "Chain Structure and Conformation of Macromolecules," Academic Press, New York, N.Y., 1982. 